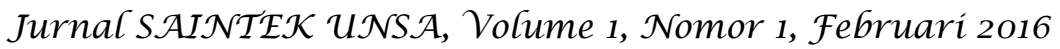

\title{
STUDI KELAYAKAN SALURAN DRAINASE JALAN SULTAN KAHARUDDIN KM. 02 KABUPATEN SUMBAWA
}

\author{
Oleh : Ady Purnama, Dini Eka Saputri
}

\begin{abstract}
ABSTRAK
Kelebihan air hujan pada suatu daerah atau kawasan dapat menimbulkan suatu masalah yaitu banjir atau genangan air seperti yang terjadi Pada ruas Jalan Sultan Kaharuddin KM.02 Kabupaten Sumbawa, terlebih pada kawasan tersebut telah dibangun sebuah taman tempat rekreasi seluruh lapisan masyarakat. Untuk mengatasi masalah genangan air ini diperlukan studi untuk mengetahui masih layak atau tidaknya saluran drainase yang ada di ruas jalan tersebut.

Data yang digunakan dalam mengkaji saluran drainase adalah data curah hujan dari stasiun Sumbawa dan Unter Iwes selama 5 tahun terkahir. Kemudian diuji konsistensinya, menghitung curah hujan maksimum, curah hujan rencana menggunakan metode Log pearson type III. Selanjutnya menghitung instensitas curah hujan dan debit air saluran.

Dari hasil analisa menunjukkan bahwa saluran eksisting tidak layak karena tidak dapat menampung debit air baik itu debit air hujan dan debit air kotor. Bahkan setelah dilakukan Langkah pertama penyelesaian yaitu Normalisasi saluran, dimensi dan debit saluran masih tidak dapat mencukupi untuk menampung debit rencana, sehingga Upaya penanganan pada saluran yang tidak layak tersebut yaitu dengan mendesain ulang dimensi saluran sehinggan air tidak meluap dan dapat mengalir dengan hasil rencana pada saluran Kanan dan Kiri $B=1.2 \mathrm{~m}, b=0.5 \mathrm{~m}, h=1 \mathrm{~m}$, kemiringan dasar saluran sebesar $1 \%$ dan debit hasil analisa sebesar $=26.4039 \mathrm{~m}^{3} / d t$. Dengan demikian debit yang dihasilkan oleh rencana dimensi ulang lebih besar dari debit rencana sehingga saluran pada ruas jalan Sultan Kaharuddin KM.02 Kabupaten Sumbawa mampu untuk menampung dan mengalirkan air agar tidak terjadi genangan kembali .
\end{abstract}

Kata kunci : Saluran Drainase, Genangan air, Kapasitas saluran, Desain Rencana, Kelayakan Saluran.

\section{PENDAHULUAN}

Pembangunan suatu gedung atau infrastruktur pada suatu daerah atau kawasan sebaiknya perlu memperhatikan infrastruktur pendukung seperti saluran drainase agar tidak mengganggu aktivitas dan kenyamanan pengguna dan menyebabkan kerusakan pada gedung atau infrastruktur itu sendiri.Kelebihan air hujan pada suatu daerah atau kawasan dapat menimbulkan suatu masalah yaitu banjir atau genangan air, sehingga diperlukan adanya 


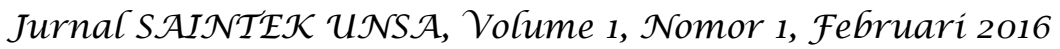

saluran drainase yang berfungsi menampung air hujan dan kemudian mengalirkannya ke kolam penampungan atau ke sungai.Saluran drainase di jalan Sultan Kaharuddin KM.02 tepatnya (Depan Taman Genang Genis) yang baru-baru ini telah dibangun dan mulai dijadikan obyek wisata masih belum diperhatikan, terbukti masih adanya genangan pada saat hujan.

Berdasarkan identifikasi lapangan kapasitas saluran drainase yang kerap mengalami banjir atau genangan air menurun akibat menumpuknya sampah, rumput, tumbuh - tumbuhan liar serta kurangnya kesadaran masyarakat setempat untuk menjaga kebersihan saluran sehingga saluran tidak berfungsi secara optimal. Guna mengendalikan terjadinya genangan, maka perlu dilakukan analisa kelayakan terhadap drainase yang ada untuk mengetahui kapasitas saluran sehingga dapat ditentukan dimensi saluran rencana.

\section{METODE PENELITIAN}

Metode dalam penulisan ini menggunakan metode Metode observasi, Metode dokumentasi dan Metode literatur atau kepustakaan. Data - data yang digunakan dalam penelitian ini berasal dari beberapa instansi terkait. Langkahlangkah penyusunan skripsi ini adalah :

1. Pengumpulan data yaitu data curah hujan, data penduduk dan data hidrolika ( pengamatan langsung).

2. Pengolahan data, urutan pengolahan data yaitu :
a. Analisis Hidrologi ( analisa data curah hujan ).
b. Perhitungan kapasitas saluran eksisting.
c. Pehitungan debit rencana.
d. Perhitungan normalisasi saluran.
e. Perencanaan ulang dimensi saluran ( jika tidak memenuhi ). 


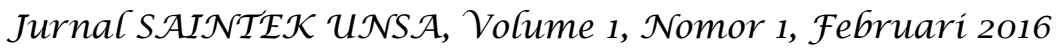

\section{Diagram Alir Penelitian}

Diagram alir Sudi Kelayakan Saluran Drainase Jalan Sultan kaharuddin KM.02 Kabupaten Sumbawa dapat dilihat pada gamar berikut :

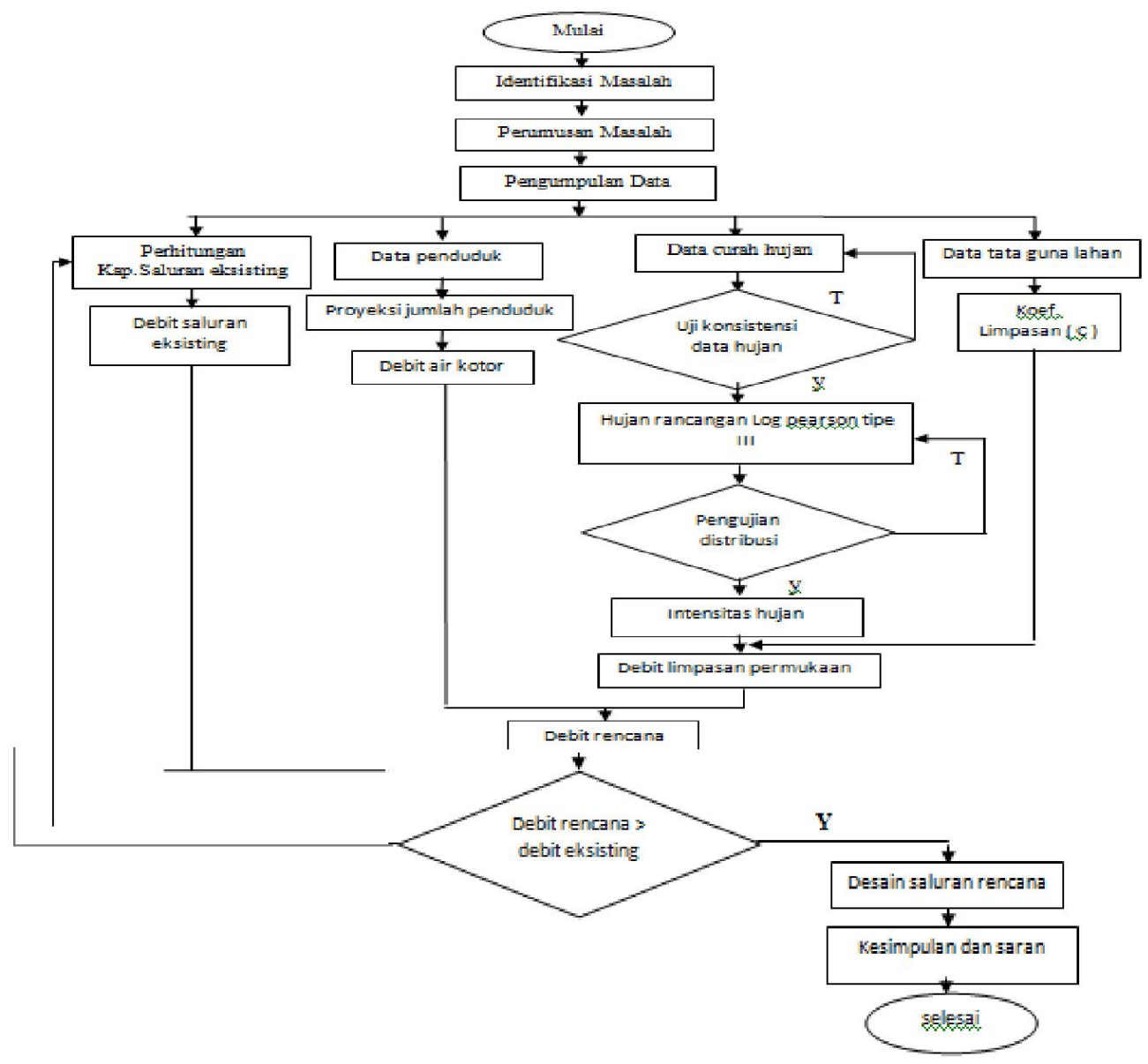

Gambar 3.3 Kerangka Penelitian

\section{HASIL DAN PEMBAHASAN}

\section{Distribusi Log Pearson III}

a. Ubah data ke dalam bentuk logaritmis, $X=\log X$

b. Hitung harga rata-rata:

$$
\begin{gathered}
\frac{n}{\sum \log X i} \\
\frac{i}{\log X=1}
\end{gathered}
$$




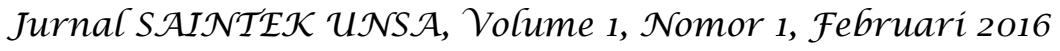

c. Hitung harga simpangan baku :

$$
\begin{aligned}
& s=\left(\begin{array}{cc}
\frac{n}{\Sigma(\log X i-\log X)^{2}} & 0,5
\end{array}\right) \\
& n-1 i=1
\end{aligned}
$$

d. Hitung koefisien kemencengan :

$$
\begin{aligned}
& \frac{n}{\sum(\log X i-\log X)^{3}} \\
& \mathrm{i}=1 \\
& G=(n-1) \cdot(n-2) \cdot S^{3}
\end{aligned}
$$

\begin{tabular}{|c|c|c|c|c|c|}
\hline No & $\mathbf{X i}$ & $\log X i$ & $\log X i-\log X$ & $(\log X i-\log X)^{2}$ & $(\log X i-\log X)^{3}$ \\
\hline 1 & 42.17 & 1.6250 & -0.2188 & 0.0479 & -0.0105 \\
\hline 2 & 44 & 1.6435 & -0.2003 & 0.0401 & -0.0080 \\
\hline 3 & 62.67 & 1.7970 & -0.0467 & 0.0022 & -0.0001 \\
\hline 4 & 88.67 & 1.9478 & 0.1040 & 0.0108 & 0.0011 \\
\hline 5 & 160.5 & 2.2055 & 0.3617 & 0.1309 & 0.0473 \\
\hline \multicolumn{2}{|c|}{ Jumlah } & 9,8166 & 9.2187 & 0.0000 & 0.2318 \\
\hline \multicolumn{2}{|c|}{ Rerata } & 1.8437 & & & \\
\hline \multicolumn{2}{|c|}{$S \log x$} & 0.2407 & & & \\
\hline \multicolumn{2}{|c|}{ Cs } & 0.1783 & & & \\
\hline
\end{tabular}

e. Hitung logaritma hujan atau banjir dengan periode ulang $T$ dengan rumus :

$\log X_{T}=\log X+K . S$

Tabel 2. Perhitungan Deviasi Standar Dan Koefisien Kemencengan (Cs)

Sumber :Hasil analisis 


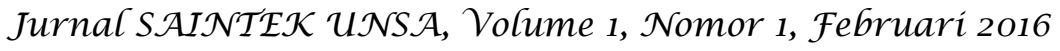

Tabel 3. Faktor Frekuensi K Distribusi Log Pearso n type III Koefisien Asimetri Cs positif

\begin{tabular}{|c|c|c|c|c|c|c|c|c|}
\hline \multirow{2}{*}{$\begin{array}{c}\text { Skew } \\
\text { coeff }\end{array}$} & \multicolumn{7}{|c|}{ Averange recurrence interval in years } \\
\cline { 2 - 8 } (Cs) & 1,01 & 1,053 & 1,111 & 1,25 & 2 & 5 & 10 & 25 \\
\cline { 2 - 9 } & 99 & 95 & 90 & 80 & 50 & 20 & 10 & 4 \\
\hline 0,2 & -2.178 & -1.586 & -1.258 & -0.850 & -0.033 & 0.830 & 1.301 & 1.818 \\
\hline 0.1783 & -2.194 & -1.593 & -1.261 & -0.849 & -0.030 & 0.831 & 1.299 & 1.811 \\
\hline 0.1 & -2.252 & -1.616 & -1.270 & -0.846 & -0.017 & 0.836 & $1 ., 292$ & 1.785 \\
\hline
\end{tabular}

Sumber : Hasil analisa

Tabel 4. Curah Hujan Rancangan DAS Unter Iwes

\begin{tabular}{|c|c|c|c|c|c|c|c|}
\hline $\begin{array}{c}\text { Tr } \\
\text { (Tahun) }\end{array}$ & $\begin{array}{c}\text { Pr } \\
(\%)\end{array}$ & Cs & S Log X & $\log X$ & K & $\log X t$ & Xt \\
\hline 2 & 50 & 0.2358 & 0.1783 & 1.8437 & $-0,030$ & 1.8343 & 68.281 \\
\hline 5 & 20 & 0.2358 & 0.1783 & 1.8437 & 0,831 & 2.0431 & 110.433 \\
\hline
\end{tabular}

Sumber : Hasil analisa

\section{Intensitas Hujan Jam - Jaman}

Besar hujan rancangan untuk kala ulang 5 tahun adalah X5 $=110.433 \mathrm{~mm} / \mathrm{jam}$ (dapat dilihat pada tabel 4.9) .

untuk perhitungan waktu konsentrasi (tc) :

$\mathrm{tc}=\mathrm{to}+\mathrm{td}$

to $=5$ menit ( untuk daerah permukaan diperkeras $)=0.083$ jam

$\mathrm{td}=0.0195\left[\begin{array}{l}\underline{L} \\ \mathrm{~V} I\end{array}\right]^{0.77}$

$\mathrm{td}=0.0195 \times\left[\frac{475}{\sqrt{0.002}}\right]^{0.77}$

$=24,5580$ menit $=0.4093 \mathrm{jam}$

tc $=0.083+0.4093=0.4923 \mathrm{jam}$

untuk perhitungan selengkapnya dapat dilihat pada tabel 5 . 


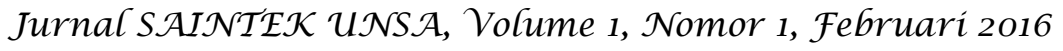

Tabel 5. Waktu Konsentrasi

\begin{tabular}{|l|l|l|l|l|l|l|l|}
\hline \multirow{2}{*}{ No } & Lokasi & Saluran & $\begin{array}{l}\text { L } \\
\text { (m) }\end{array}$ & $\mathbf{S}$ & $\begin{array}{l}\text { To } \\
\text { (jam) }\end{array}$ & $\begin{array}{l}\text { td } \\
\text { (jam) }\end{array}$ & $\begin{array}{l}\text { tc } \\
\text { (jam) }\end{array}$ \\
\hline \multirow{2}{*}{1} & $\begin{array}{c}\text { Jalan Sultan kaharuddin } \\
\text { Km.02 }\end{array}$ & Kanan & 475 & 0.002 & 0.083 & 0.4093 & 0.4923 \\
\cline { 3 - 8 } & Kiri & 475 & 0.002 & 0.083 & 0.4093 & 0.4923 \\
\hline
\end{tabular}

Sumber : Hasil analisa

Dengan rumus monobe dapat dicari intensitas hujan jam - jaman sebagai berikut:

$$
\begin{aligned}
I & =\frac{\mathrm{R} 24}{24 \mathrm{tc}} \underline{24}^{2 / 3} \\
& =\frac{110.433}{24 \times 0.4923} \\
& =61.4854 \mathrm{~mm} / \mathrm{jam}
\end{aligned}
$$

Untuk perhitungan selengkapnya dapat dilihat pada tabel 6

Tabel 6. Intensitas Hujan Jam-Jaman

\begin{tabular}{|c|c|c|c|}
\hline No & Lokasi & Saluran & $\begin{array}{c}\text { I } \\
\text { (mm/jam) }\end{array}$ \\
\hline \multirow{2}{*}{1} & Jalan Sultan kaharuddin & Kanan & 61.4854 \\
\cline { 2 - 4 } & Km.02 & Kiri & 61.4854 \\
\hline
\end{tabular}

\section{Koefisien Aliran Permukaan ( C)}

Tabel 7. Koefisien Pengaliran

\begin{tabular}{|c|c|c|c|}
\hline Lokasi & STA & Cm ( Kanan ) & Cm ( Kiri ) \\
\hline \multirow{3}{*}{ Jalan Sultan Kaharuddin } \\
KM.02 & $0+000-0+025$ & 0.50 & 0.60 \\
\cline { 2 - 4 } & $0+025-0+050$ & 0.50 & 0.60 \\
\cline { 2 - 4 } & $0+050-0+075$ & 0.35 & 0.40 \\
\cline { 2 - 4 } & $0+075-0+100$ & 0.35 & 0.60 \\
\hline
\end{tabular}




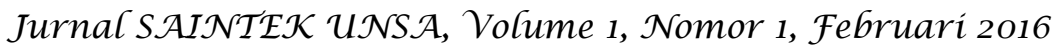

\begin{tabular}{|c|c|c|c|}
\hline Kabupaten Sumbawa & $0+100-0+125$ & 0.35 & 0.60 \\
\cline { 2 - 4 } & $0+125-0+150$ & 0.60 & 0.60 \\
\cline { 2 - 4 } & $0+150-0+175$ & 0.60 & 0.60 \\
\cline { 2 - 4 } & $0+175-0+200$ & 0.60 & 0.60 \\
\hline & $0+200-0+225$ & 0.50 & 0.60 \\
\hline $0+225-0+250$ & 0.50 & 0.40 \\
\hline & $0+250-0+275$ & 0.50 & 0.22 \\
\cline { 2 - 4 } & $0+275-0+300$ & 0.60 & 0.40 \\
\cline { 2 - 4 } & $0+300-0+325$ & 0.60 & 0.40 \\
\hline $0+325-0+350$ & 0.60 & 0.60 \\
\hline & & 0.60 & 0.22 \\
\hline & & 0.60 & 0.40 \\
\hline & $0+350-0+375$ & 0.50 & 0.40 \\
\hline $0+375-0+400$ & 0.50 & 0.50 \\
\hline $0+450-0+475$ & 0.50 & 0.22 \\
\hline
\end{tabular}

\section{Sumber : Hasil Analisa}

Debit Banjir Rencana

Perhitungan Debit Air Limpasan

Perhitungan debit banjir rencana metode ini menggunakan persmaaan :

Qr $=0.2778 \times C \times I \times A$

Contoh perhitungan untuk saluran kanan STA $0+00-0+025$ :

Koefisien limpasan $\quad=0.50$

Intensitas hujan $\left(1^{5}\right)=61.485 \mathrm{~mm} / \mathrm{jam}$

Luas catchment $(A)=\underline{0.02472}=0.00130$

19

Sehingga debit puncak dengan kala ulang 5 tahun dengan metode rasional pada saluran kanan diperoleh besar:

$$
\begin{aligned}
\text { Q5 } & =0.2778 \times C \times I \times A \\
& =0.2778 \times 0.50 \times 61.485 \times 0.00130 \\
& =0.011 \mathrm{~m}^{3} / \mathrm{det}
\end{aligned}
$$

Sedangkan Contoh perhitungan untuk saluran kiri STA $0+000-0+025$ : 


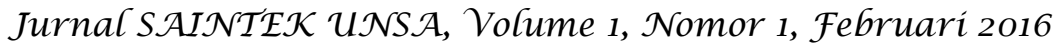

$$
\begin{aligned}
\text { Koefisien limpasan } & =0.60 \\
\text { Intensitas hujan }\left(I^{5}\right) & =61.485 \mathrm{~mm} / \mathrm{jam} \\
\text { Luas catchment }(\mathrm{A}) & =\underline{0.02681}=0.00141
\end{aligned}
$$

Sehingga debit puncak dengan kala ulang 5 tahun dengan metode rasional pada saluran kanan diperoleh besar :

$$
\begin{aligned}
\text { Q5 } & =0.2778 \times C \times I \times A \\
& =0.2778 \times 0.60 \times 61.485 \times 0.00141 \\
& =0.014 \mathrm{~m}^{3} / \operatorname{det}
\end{aligned}
$$

\begin{tabular}{|c|c|c|c|c|c|c|c|c|c|c|}
\hline Lokasi & Saluran Kanan & $\begin{array}{c}\text { Koef } \\
\text { Limpasan } \\
\text { (C) }\end{array}$ & $\begin{array}{c}\text { Intensitas } \\
\text { Hujan } \\
\text { (I) }\end{array}$ & $\begin{array}{c}\text { Luas } \\
\text { Catch } \\
\left(\mathbf{K m}^{2}\right)\end{array}$ & $\mathrm{Qp}$ & Saluran Kiri & $\begin{array}{l}\text { Koef } \\
\text { Limp } \\
\text { asan } \\
\text { (C) } \\
\end{array}$ & $\begin{array}{c}\text { Intensitas } \\
\text { Hujan } \\
\text { (I) }\end{array}$ & $\begin{array}{l}\text { Luas } \\
\text { Catch } \\
\left(\mathrm{Km}^{2}\right)\end{array}$ & $\mathrm{Qp}$ \\
\hline \multirow{20}{*}{$\begin{array}{c}\text { Jn Sultan } \\
\text { Kaharuddin } \\
\text { KM.02 } \\
\text { Kabupaten } \\
\text { Sumbawa }\end{array}$} & $0+000-0+025$ & 0.50 & 61.485 & 0.00130 & 0.011 & $0+000-0+025$ & 0.60 & 61.485 & 0.00141 & 0.014 \\
\hline & $0+025-0+050$ & 0.50 & 61.485 & 0.00130 & 0.011 & $0+025-0+050$ & 0.60 & 61.485 & 0.00141 & 0.014 \\
\hline & $0+050-0+075$ & 0.35 & 61.485 & 0.00130 & 0.008 & $0+050-0+075$ & 0.40 & 61.485 & 0.00141 & 0.010 \\
\hline & $0+075-0+100$ & 0.35 & 61.485 & 0.00130 & 0.008 & $0+075-0+100$ & 0.60 & 61.485 & 0.00141 & 0.014 \\
\hline & $0+100-0+125$ & 0.35 & 61.485 & 0.00130 & 0.008 & $0+100-0+125$ & 0.60 & 61.485 & 0.00141 & 0.014 \\
\hline & $0+125-0+150$ & 0.60 & 61.485 & 0.00130 & 0.013 & $0+125-0+150$ & 0.60 & 61.485 & 0.00141 & 0.014 \\
\hline & $0+150-0+175$ & 0.60 & 61.485 & 0.00130 & 0.013 & $0+150-0+175$ & 0.60 & 61.485 & 0.00141 & 0.014 \\
\hline & $0+175-0+200$ & 0.60 & 61.485 & 0.00130 & 0.013 & $0+175-0+200$ & 0.60 & 61.485 & 0.00141 & 0.014 \\
\hline & $0+200-0+225$ & 0.50 & 61.485 & 0.00130 & 0.011 & $0+200-0+225$ & 0.60 & 61.485 & 0.00141 & 0.014 \\
\hline & $0+225-0+250$ & 0.50 & 61.485 & 0.00130 & 0.011 & $0+225-0+250$ & 0.40 & 61.485 & 0.00141 & 0.010 \\
\hline & $0+250-0+275$ & 0.50 & 61.485 & 0.00130 & 0.011 & $0+250-0+275$ & 0.22 & 61.485 & 0.00141 & 0.005 \\
\hline & $0+275-0+300$ & 0.60 & 61.485 & 0.00130 & 0.013 & $0+275-0+300$ & 0.40 & 61.485 & 0.00141 & 0.010 \\
\hline & $0+300-0+325$ & 0.60 & 61.485 & 0.00130 & 0.013 & $0+300-0+325$ & 0.40 & 61.485 & 0.00141 & 0.010 \\
\hline & $0+325-0+350$ & 0.60 & 61.485 & 0.00130 & 0.013 & $0+325-0+350$ & 0.60 & 61.485 & 0.00141 & 0.014 \\
\hline & $0+350-0+375$ & 0.60 & 61.485 & 0.00130 & 0.013 & $0+350-0+375$ & 0.22 & 61.485 & 0.00141 & 0.005 \\
\hline & $0+375-0+400$ & 0.60 & 61.485 & 0.00130 & 0.013 & $0+375-0+400$ & 0.40 & 61.485 & 0.00141 & 0.010 \\
\hline & $0+400-0+425$ & 0.50 & 61.485 & 0.00130 & 0.011 & $0+400-0+425$ & 0.40 & 61.485 & 0.00141 & 0.010 \\
\hline & $0+425-0+450$ & 0.50 & 61.485 & 0.00130 & 0.011 & $0+425-0+450$ & 0.50 & 61.485 & 0.00141 & 0.012 \\
\hline & $0+450-0+475$ & 0.50 & 61.485 & 0.00130 & 0.011 & $0+450-0+475$ & 0.22 & 61.485 & 0.00141 & 0.005 \\
\hline & Total & & & 0.02472 & 0.2189 & & & & 0.02681 & 0.2160 \\
\hline
\end{tabular}

Untuk hasil perhitungan selengkapnya disajikan dalam tabel 8

Tabel 8. Debit limpasan air hujan dengan kala ulang 5 tahun

Hasil : Analisa

Perhitungan Debit Air Kotor

Proyeksi Jumlah Penduduk 


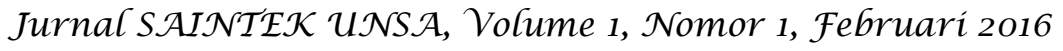

$$
\begin{aligned}
& \mathrm{Pn}=\mathrm{Po}(1+\mathrm{r})^{5} \\
& \mathrm{P} 2019=3600(1+1 \%)^{5} \\
& \mathrm{P} 2019=3780 \text { jiwa }
\end{aligned}
$$

Jadi jumlah penduduk Desa Kerato di proyeksikan pada tahun 2019 sebanyak 3780 jiwa.

Debit Air Buangan Rumah Tangga

Qk $=\underline{\text { Pn } \times 80 \% \times K a b}$

\section{A}

$\mathrm{Pn}=79$ Jiwa

$\mathrm{Kab}=0,003 \mathrm{It} / \mathrm{dt} / \mathrm{jiwa}$

Maka :

$Q k=79 \times 0.8 \times 0.003$

$$
0.02472
$$

$\mathrm{Qk}=8.8766 \mathrm{lt} / \mathrm{dt} /$ jiwa

Besarnya debit buangan untuk tiap saluran dihitung menggunakan persamaan :

Qki = Qk x Luas daerah layanan Untuk luas daerah aliran di Jalan Sultan Kaharuddin ( Kanan ) adalah :

$$
\begin{aligned}
\text { Qki } & =8.8766 \times 0.02472 \\
& =0.219 \mathrm{~m}^{3} / \mathrm{dt}
\end{aligned}
$$

Untuk hasil perhitungan selengkapnya dapat dilihat pada tabel 9 
Jurnal SAIJ $\mathcal{N} \mathcal{E} \mathcal{K}$ UNSSA, Volume 1, $\mathcal{N o m o r}$ 1, Februari 2016

Tabel 9 Debit Domestik

\begin{tabular}{|c|c|c|c|c|c|c|c|c|}
\hline Lokasi & Saluran Kanan & $\begin{array}{l}\text { Luas Catch } \\
\text { (Km 2) }\end{array}$ & $\begin{array}{c}\mathrm{Pn} \\
\text { (jiwa) } \\
\end{array}$ & $\begin{array}{c}\text { Debit Domestiks } \\
(\mathrm{m} 3 / \mathrm{dt})\end{array}$ & Saluran Kiri & $\begin{array}{c}\text { Luss Catch } \\
\text { (Km2) }\end{array}$ & $\begin{array}{c}\mathrm{Pn} \\
\text { (Jiwa) }\end{array}$ & $\begin{array}{c}\text { Debit Domestik } \\
(\mathrm{m} 3 / \mathrm{dt})\end{array}$ \\
\hline \multirow{11}{*}{$\begin{array}{l}\text { 1. Sultan Kaharnddin KM.02 } \\
\text { Kabupaten Sumbawa }\end{array}$} & $0+000-0+025$ & 0.00130 & 79 & 0.0115 & $0+000-0+025$ & 0.00141 & 81 & 0.0119 \\
\hline & $0+025-0+050$ & 0.00130 & 79 & 0.0115 & $0+025-0+050$ & 0,00141 & 81 & 0.0119 \\
\hline & $0+050-0+075$ & 0.00130 & 79 & 0.0115 & $0+050-0+075$ & 0,00141 & 81 & 0.0119 \\
\hline & $0+075-0+100$ & 0.00130 & 79 & 0.0115 & $0+075 \cdot 0+100$ & 0,00141 & 81 & 0.0119 \\
\hline & $0+100-0+125$ & 0.00130 & 79 & 0.0115 & $0+100-0+125$ & 0.00141 & 81 & 0.0119 \\
\hline & $0+125-0+150$ & 0.00130 & 79 & 0.0115 & $0+125 \cdot 0+150$ & 0,00141 & 81 & 0.0119 \\
\hline & $0+150-0+175$ & 0.00130 & 79 & 0.0115 & $0+150-0+175$ & 0.00141 & 81 & 0.0119 \\
\hline & $0+175-0+200$ & 0.00130 & 79 & 0.0115 & $0+175-0+200$ & 0.00141 & 81 & 0.0119 \\
\hline & $0+200-0+225$ & 0.00130 & 79 & 0.0115 & $0+200-0+225$ & 0,00141 & 81 & 0.0119 \\
\hline & $0+225-0+250$ & 0.00130 & 79 & 0.0115 & $0+225 \cdot 0+250$ & 0,00141 & 81 & 0.0119 \\
\hline & $0+250-0+275$ & 0.00130 & 79 & 0.0115 & $0+250-0+275$ & 0.00141 & 81 & 0.0119 \\
\hline \multirow{8}{*}{$\begin{array}{l}\text { 1.Sultan Kaharnddin KMOO2 } \\
\text { Kabupaten Sumbawa }\end{array}$} & $0+275-0+300$ & 0.00130 & 79 & 0.0115 & $0+275-0+300$ & 0,00141 & 81 & 0.0119 \\
\hline & $0+300-0+325$ & 0.00130 & 79 & 0.0115 & $0+300-0+325$ & 0,00141 & 81 & 0.0119 \\
\hline & $0+325-0+350$ & 0.00130 & 79 & 0.0115 & $0+325 \cdot 0+350$ & 0,00141 & 81 & 0.0119 \\
\hline & $0+350-0+375$ & 0.00130 & 79 & 0.0115 & $0+350-0+375$ & 0,00141 & 81 & 0.0119 \\
\hline & $0+375-0+400$ & 0.00130 & 79 & 0.0115 & $0+375-0+400$ & 0,00141 & 81 & 0.0119 \\
\hline & $0+400-0+425$ & 0.00130 & 79 & 0.0115 & $0+400-0+425$ & 0,00141 & 81 & 0.0119 \\
\hline & $0+425-0+450$ & 0.00130 & 79 & 0.0115 & $0+425-0+450$ & 0.00141 & 81 & 0.0119 \\
\hline & $0+450-0+475$ & 0.00130 & 79 & 0.0115 & $0+450-0+475$ & 0.00141 & 81 & 0.0119 \\
\hline Total & & 0.02472 & & 0.2194 & & 0,02681 & & 0.2255 \\
\hline
\end{tabular}

Hasil : Analisa

Debit Air Buangan Rumah Tangga

Debit total yang digunakan untuk merencanakan saluran yang berasal dari limpasan air hujan dan air buangan rumah tangga yang kemudian dijumlahkan untuk mendapatkan debit rencana saluran.

Contoh perhitungan untuk saluran kanan STA $0+00-0+025$

$$
\begin{aligned}
Q r & =Q p+Q k i \\
& =0.011+0.0115 \\
& =0.0227 \mathrm{~m}^{3} / \mathrm{dt}
\end{aligned}
$$

Contoh perhitungan untuk saluran kiri STA $0+00-0+025$

$$
\begin{aligned}
Q r & =Q p+Q k i \\
& =0.014+0.0119 \\
& =0.0263 \mathrm{~m}^{3} / \mathrm{dt}
\end{aligned}
$$

Untuk perhitungan selengkapnya disajikan dalam tabel 10 


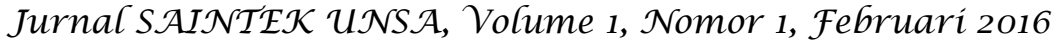

\begin{tabular}{|c|c|c|c|c|c|c|c|c|}
\hline Lolinsi & Saluran Kanan & $\underset{\left(\mathrm{m}^{3} / \mathrm{dt}\right)}{\mathrm{pp}}$ & $\begin{array}{c}\text { Debit } \\
\text { Domestik } \\
\left(\mathrm{m}^{3} / \mathrm{dif}\right)\end{array}$ & $\begin{array}{c}\text { Debit Rencana } \\
\text { Qr } \\
\left(\mathrm{m}^{3} / \mathrm{d}\right) \\
\end{array}$ & Saluran Kiri & $\underset{\left(\mathrm{m}^{3} / \mathrm{d} t\right)}{\mathrm{Qp}}$ & $\begin{array}{c}\text { Debit } \\
\text { Domestik } \\
\left(\mathbf{m}^{3} / \mathrm{d}\right)\end{array}$ & $\begin{array}{c}\text { Debit rencana } \\
Q \mathrm{r} \\
\mathrm{m}^{3 / \mathrm{d} 0} \\
\end{array}$ \\
\hline \multirow{19}{*}{$\begin{array}{l}\text { 1.Sultan kaharuddin KM.02 } \\
\text { Kabupaten Sumbawa }\end{array}$} & $0+000-0+025$ & 0.011 & 0.0115 & 0.0227 & $0+000-0+025$ & 0.014 & 0.0119 & 0.0263 \\
\hline & $0+025-0+050$ & 0.011 & 0.0115 & 0.0227 & $0+025-0+050$ & 0.014 & 0.0119 & 0.0263 \\
\hline & $0+050-0+075$ & 0.008 & 0.0115 & 0.0193 & $0+050-0+075$ & 0.010 & 0.0119 & 0.0215 \\
\hline & $0+075-0+100$ & 0.008 & 0.0115 & 0.0193 & $0+075-0+100$ & 0.014 & 0.0119 & 0.0263 \\
\hline & $0+100-0+125$ & 0.008 & 0.0115 & 0.0193 & $0+100-0+125$ & 0.014 & 0.0119 & 0.0263 \\
\hline & $0+125-0+150$ & 0.013 & 0.0115 & 0.0249 & $0+125-0+150$ & 0.014 & 0.0119 & 0.0263 \\
\hline & $0+150-0+175$ & 0.013 & 0.0115 & 0.0249 & $0+150-0+175$ & 0.014 & 0.0119 & 0.0263 \\
\hline & $0+175-0+200$ & 0.013 & 0.0115 & 0.0249 & $0+175-0+200$ & 0.014 & 0.0119 & 0.0263 \\
\hline & $0+200-0+225$ & 0.011 & 0.0115 & 0.0227 & $0+200-0+225$ & 0.014 & 0.0119 & 0.0263 \\
\hline & $0+225-0+250$ & 0011 & 0.0115 & 0.0227 & $0+225-0+250$ & 0.010 & 0.0119 & 0.0215 \\
\hline & $0+250-0+275$ & 0.011 & 0.0115 & 0.0227 & $0+250-0+275$ & 0.005 & 0.0119 & 0.0172 \\
\hline & $0+275-0+300$ & 0.013 & 0.0115 & 0.0249 & $0+275-0+300$ & 0.010 & 0.0119 & 0.0215 \\
\hline & $0+300-0+325$ & 0.013 & 0.0115 & 0.0249 & $0+300-0+325$ & 0.010 & 0.0119 & 0.0215 \\
\hline & $0+325-0+350$ & 0.013 & 0.0115 & 0.0249 & $0+325-0+350$ & 0.014 & 0.0119 & 0.0263 \\
\hline & $0+350-0+375$ & 0.013 & 0.0115 & 0.0249 & $0+350-0+375$ & 0.005 & 0.0119 & 0.0172 \\
\hline & $0+375-0+400$ & 0.013 & 0.0115 & 0.0249 & $0+375-0+400$ & 0.010 & 0.0119 & 0.0215 \\
\hline & $0+400-0+425$ & 0.011 & 0.0115 & 0.0227 & $0+400-0+425$ & 0.010 & 0.0119 & 0.0215 \\
\hline & $0+425-0+450$ & 0.011 & 0.0115 & 0.0227 & $0+425-0+450$ & 0.012 & 0.0119 & 0.0239 \\
\hline & $0+450-0+475$ & 0.011 & 0.0115 & 0.0227 & $0+450-0+475$ & 0.005 & 0.0119 & 0.0172 \\
\hline Total & & 0.2189 & 0.2194 & 0.4383 & & 0.2160 & 0.2255 & 0.4415 \\
\hline
\end{tabular}

Tabel 10. Debit Rencana Saluran

Hasil : Analisa

\begin{tabular}{|c|c|c|c|}
\hline No & Lokasi & Saluran & Debit Rencana \\
\hline 1 & Jalan Sultan Kaharuddin & Kanan & 0.4383 \\
\cline { 3 - 4 } & KM.02 Kabupaten Sumbawa & Kiri & 0.4415 \\
\hline
\end{tabular}

Tabel 11. Debit Total Rencana STA $0+025$ sampai STA $0450+0475$

Hasil : Analisa

Penampang Trapesium

Perhitungan Untuk Saluran Kanan adalah :

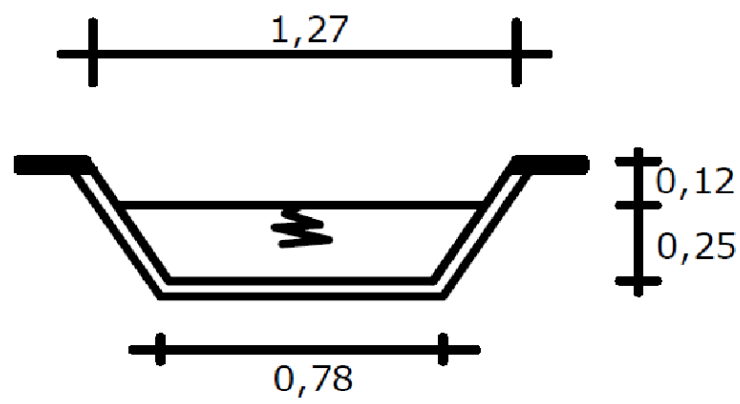

a) Lebar dinding saluran (x)

$$
X=\underline{B-b}=\underline{1.27-0.78}=0.245 \mathrm{~m}
$$




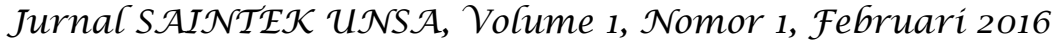

b) Kemiringan dinding saluran ( $m$ )

$$
\begin{array}{rl}
\underline{h} & =\underline{x} \\
m & b \\
\underline{0.25} & =\underline{0,245} \\
m & =0.78 \\
m & =1 ., 2671
\end{array}
$$

c) Luas penampang saluran ( $A$ )

$$
\begin{aligned}
A & =(b+m \times h) \times h \\
& =(0.78+1.2671 \times 0.25) \times 0.25 \\
& =1.0941 \times 0.25 \\
& =0.2712 \mathrm{~m}^{2}
\end{aligned}
$$

d) Keliling basah saluran ( P )

$$
\begin{aligned}
P & =b+2 h \vee m^{2}+1^{2} \\
& =0.78+2 \times 0.25 \vee 1.2671^{2}+1 \\
& =0.78+0,5.0 \times 1.6141 \\
& =1, .5803 \mathrm{~m}
\end{aligned}
$$

e) Jari-jari hidrolis ( R )

$$
\begin{aligned}
R= & \underline{A} \\
= & \underline{0.2712} \\
& 1.5803 \\
= & 0 ., 1716 \mathrm{~m}
\end{aligned}
$$

f) Debit yang mampu ditampung oleh saluran ( $Q$ )

$$
\begin{aligned}
Q & =\left(1 / n \times R^{2 / 3} \times I^{1 / 2}\right) \times A \\
& =\left(1 / 0.025 \times 0.1716^{2 / 3} \times 0.0015^{1 / 2}\right) \times 0.2712 \\
& =0,1298 \mathrm{~m}^{3} / \mathrm{dt} \\
V & =1 / \mathrm{n} \times \mathrm{R}^{2 / 3} \times \mathrm{I}^{1 / 2} \\
& =1 / 0.025 \times 0.1716^{2 / 3} \times 0.0015^{1 / 2} \\
& =0.4785 \mathrm{~m} / \mathrm{dt}
\end{aligned}
$$




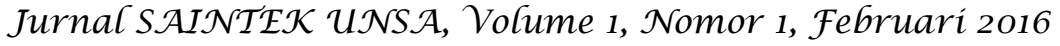

\begin{tabular}{|c|c|c|c|c|c|c|c|c|c|c|c|c|c|c|}
\hline \multirow{2}{*}{ No } & \multirow{2}{*}{ Lokasi } & \multirow{2}{*}{ Saluran } & \multirow{2}{*}{$\begin{array}{c}\mathrm{L} \\
\text { (III) }\end{array}$} & \multicolumn{3}{|c|}{ Dimensi } & \multirow{2}{*}{$\mathrm{m}$} & & & \multirow{2}{*}{$\begin{array}{c}\mathrm{A} \\
\left(\mathrm{m}^{2}\right)\end{array}$} & \multirow{2}{*}{\begin{tabular}{|c|}
$\mathbf{P}$ \\
$(\mathrm{m})$ \\
\end{tabular}} & \multirow{2}{*}{$\begin{array}{c}\mathbf{R} \\
(\mathbf{m}) \\
\end{array}$} & \multirow{2}{*}{$\begin{array}{c}V \\
(\mathrm{~m} / \mathrm{dt})\end{array}$} & \multirow{2}{*}{$\begin{array}{c}Q \\
\left(\mathrm{~m}^{3} / \mathrm{dt}\right)\end{array}$} \\
\hline & & & & $\mathrm{b}$ & B & $\mathrm{h}$ & & & & & & & & \\
\hline \multirow[t]{2}{*}{1} & \multirow{2}{*}{$\begin{array}{l}\text { Jalan Sultan Kaharuddin } \\
\text { KM02 }\end{array}$} & Kanan & 475 & 0.78 & 1.27 & 0.25 & 1.2671 & 0.0015 & 0.025 & 0.2712 & 1.5803 & 0.1716 & 0.4785 & 0.1298 \\
\hline & & Kiri & 475 & 1.12 & 1.15 & 0.19 & 0.0689 & 0.0015 & 0.025 & 0.2202 & 1.5095 & 0.1459 & 0.4293 & 0.0945 \\
\hline
\end{tabular}

Tabel. 12 Kapasitas Saluran Eksisting

Sumber : Hasil Analisa

Tabel 13 Perbandingan Debit Kapasitas Dengan Debit Rencana

\begin{tabular}{|c|c|c|c|c|c|c|}
\hline No & Lokasi & Saluran & $\begin{array}{c}\text { Debit } \\
\text { Rencana Qr } \\
\left(\mathbf{m}^{\mathbf{3}} / \mathbf{d t}\right)\end{array}$ & $\begin{array}{c}\mathbf{Q} \\
\text { Eksisting } \\
\left(\mathbf{m}^{\mathbf{3}} / \mathrm{dt}\right)\end{array}$ & $\begin{array}{c}\text { Selisih Debit } \\
\left(\mathbf{m}^{\mathbf{3}} / \mathrm{dt}\right)\end{array}$ & Keterangan \\
\hline \multirow{2}{*}{1} & $\begin{array}{c}\text { J.Sultan Kaharuddin } \\
\text { KM.02 }\end{array}$ & Kanan & 0.4383 & 0.1298 & -0.309 & $\begin{array}{c}\text { Saluran Tidak } \\
\text { Layak }\end{array}$ \\
\cline { 2 - 6 } & Kiri & 0.4415 & 0.0945 & -0.3470 & $\begin{array}{c}\text { Saluran Tidak } \\
\text { Layak }\end{array}$ \\
\hline
\end{tabular}

Sumber : Hasil Analisa

\section{Analisis Normalisasi Saluran}

Penampang Trapesium Normalisasi Kanan

Perhitungan Untuk Normalisasi Saluran Kanan

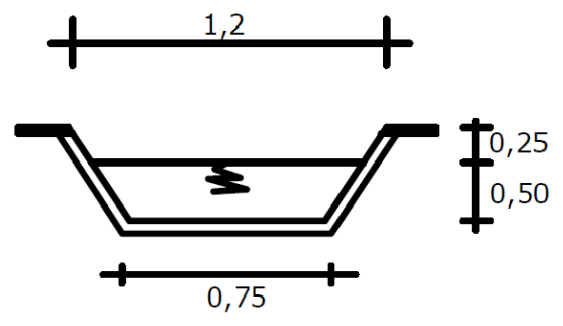

a) Lebar

$$
x=\underline{B-b}=\underline{1.2-0,75}=0.225 \mathrm{~m}
$$

2

2

b) Kemiringan dinding saluran ( $\mathrm{m}$ )

$$
\begin{array}{rl}
\underline{h} & =\underline{x} \\
m & b \\
\underline{0.50} & =\underline{0.225} \\
m & =0.75
\end{array}
$$


$m=0.5970$

c) Luas pnampang saluran ( $A$ )

$$
\begin{aligned}
A & =(b+m \times h) \times h \\
& =(0.75+0.5970 \times 0.50) \times 0.50 \\
& =1.05 \times 0.50 \\
& =0.5276 \mathrm{~m}^{2}
\end{aligned}
$$

\begin{tabular}{|c|c|c|c|c|c|c|c|c|c|c|c|c|c|c|}
\hline \multirow{2}{*}{$\mathrm{N}_{0}$} & \multirow{2}{*}{ Lokasi } & \multirow{2}{*}{ Saluran } & \multirow{2}{*}{$\begin{array}{c}\mathrm{L} \\
(\mathbf{m})\end{array}$} & \multicolumn{3}{|c|}{ Dimensi } & \multirow{2}{*}{ m } & \multirow[t]{2}{*}{ I } & \multirow[t]{2}{*}{ n } & \multirow{2}{*}{$\begin{array}{c}\mathbf{A} \\
\left(\mathbf{m}^{2}\right)\end{array}$} & \multirow{2}{*}{$\begin{array}{c}\mathbf{P} \\
(\mathrm{m})\end{array}$} & \multirow{2}{*}{$\begin{array}{c}\mathrm{R} \\
(\mathrm{m})\end{array}$} & \multirow{2}{*}{$\underset{(\mathbf{m} / \mathrm{dt})}{\mathrm{V}}$} & \multirow{2}{*}{$\begin{array}{c}Q \\
\left(\mathbf{m}^{3} / \mathrm{d} t\right)\end{array}$} \\
\hline & & & & b & B & $\mathrm{h}$ & & & & & & & & \\
\hline \multirow[t]{2}{*}{1} & $\begin{array}{l}\text { Jalan Sultant } \\
\text { Kaharuddin }\end{array}$ & Kanan & 475 & 0.75 & 1.2 & 0.50 & 0.3317 & 0.0015 & 0.025 & 0.4606 & 1.8088 & 0.2547 & 0.6224 & 0.3454 \\
\hline & KM.02 & Kiri & 475 & 0.6 & 1 & 0.50 & 0.6633 & 0.0015 & 0.025 & 0.4690 & 1.8060 & 0.2597 & 0.6306 & 0.2957 \\
\hline
\end{tabular}

d) Keliling basah saluran ( $P$ )

$$
\begin{aligned}
P & =b+2 h \vee m^{2}+1^{2} \\
& =0.75+2 \times 0.50 \vee 0.5970^{2}+1 \\
& =0.75+1 \times 1.1647 \\
& =1.9205 \mathrm{~m}
\end{aligned}
$$

Tabel 14. Kapasitas Saluran Normalisasi

Sumber : Hasil Analisa

Tabel. 15 Perbandingan Debit Kapasitas Normalisasi Dengan Debit Rencana

\begin{tabular}{|c|c|c|c|c|c|c|}
\hline No & Lokasi & Saluran & $\begin{array}{c}\text { Debit Rencana } \\
\mathbf{Q r} \\
\left(\mathbf{m}^{\mathbf{3}} / \mathbf{d t}\right)\end{array}$ & $\begin{array}{c}\text { Q Normalisasi } \\
\left(\mathbf{m}^{3} / \mathbf{d t}\right)\end{array}$ & $\begin{array}{c}\text { Selisih Debit } \\
\left(\mathbf{~ m}^{3} / \mathbf{d t}\right)\end{array}$ & Keterangan \\
\hline \multirow{2}{*}{1} & $\begin{array}{c}\text { Jl.Sultan Kaharuddin } \\
\text { KM.02 }\end{array}$ & Kanan & 0.4383 & 0.3454 & -0.0929 & Saluran Tidak Layak \\
\cline { 2 - 7 } & Kiri & 0.4415 & 0.2957 & -0.1458 & Saluran Tidak Lavak \\
\hline
\end{tabular}

Sumber : Hasil Analisa

\section{Perencanaan Saluran}

Kapasitas saluran yang telah di Normalisasi tidak mampu lagi menampung debit limpasan air hujan dan debit air kotor buangan rumah tangga, maka dari itu perlu dilakukannya perbaikan sesuai dengan kapasitas tampungan yaitu perubahan dimensi saluran eksisting yang tidak mampu lagi menampung aliran yang masuk pada saluran tersebut. 
1) Perhitungan Untuk Saluran Kanan :

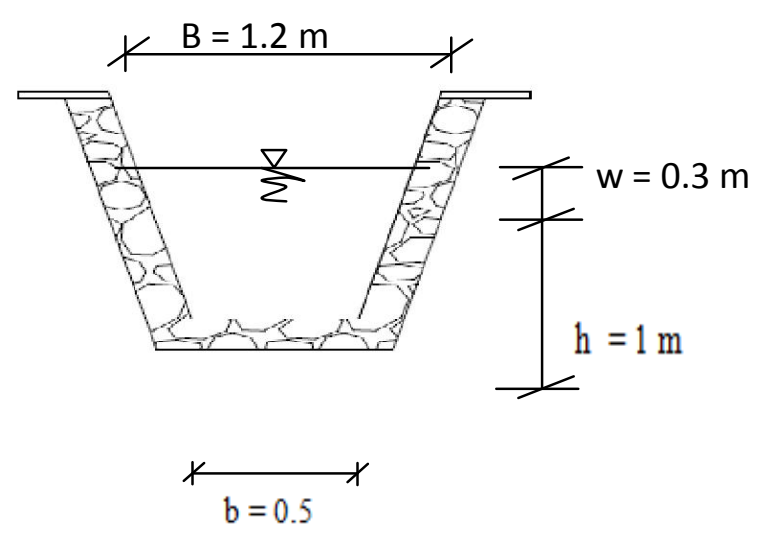

Dimensi : $\mathrm{B}=1.2 \mathrm{~m}, \mathrm{~b}=0.5 \mathrm{~m}, \mathrm{~h}=1 \mathrm{~m}$

a. Lebar dinding saluran $(\mathrm{x})$

$$
\mathrm{X}=\frac{\mathrm{B}-\mathrm{b}}{2}=\frac{1.2-0.5}{2}=0.35 \mathrm{~m}
$$

b. Kemiringan dinding saluran ( $\mathrm{m}$ )

$$
\begin{aligned}
& \frac{\mathrm{h}}{\mathrm{m}}=\underline{\mathrm{x}} \\
& \underline{\mathrm{b}}=\underline{0.35} \\
& \mathrm{~m}=0.5 \\
& \mathrm{~m}=0.7
\end{aligned}
$$

c. Luas pnampang saluran (A )

$$
\begin{aligned}
A & =(b+\mathrm{m} \times \mathrm{h}) \times \mathrm{h} \\
& =(0.5+0.7 \times 1) \times 1 \\
& =1.2 \times 1 \\
& =1.2 \mathrm{~m}^{2}
\end{aligned}
$$

d. keliling basah saluran ( P )

$$
\begin{aligned}
\mathrm{P} & =\mathrm{b}+2 \mathrm{~h} \sqrt{\mathrm{m}^{2}+1^{2}} \\
& =0.5+2 \times 1 \sqrt{0.7^{2}+1} \\
& =0.5+2 \times 1.2207 \\
& =2.9413 \mathrm{~m}
\end{aligned}
$$

e. jari-jari hidrolis ( R ) 


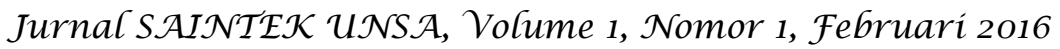

$$
\begin{aligned}
\mathrm{R} & =\frac{\mathrm{A}}{\mathrm{P}} \\
& =\frac{1.2}{2.9413} \\
& =0.4080 \mathrm{~m}
\end{aligned}
$$

f. Kemiringan Dasar Saluran ( I )

$$
\mathrm{I}=1 \%
$$

g. Kecepatan Rata - Rata Aliran Air ( V )

$$
\begin{aligned}
\mathrm{V} & =1 / \mathrm{n} \times \mathrm{R}^{2 / 3} \times \mathrm{I} 1 / 2 \\
& =1 / 0.025 \times 0.4080^{2 / 3} \times 1^{1 / 2} \\
& =22.0033 \mathrm{~m} / \mathrm{dt}
\end{aligned}
$$

h. Debit Yang Mampu ditampung Oleh Saluran ( Q )

$$
\begin{aligned}
\mathrm{Q} & =\mathrm{A} \times \mathrm{V} \\
& =1.2 \times 22.0033 \\
& =26.4039 \mathrm{~m}^{3} / \mathrm{dt}>\text { Q Rencana } 0.4388 \mathrm{~m}^{3} / \mathrm{dt}
\end{aligned}
$$

Maka dimensi rencana dapat diterima

i. Bilangan Froud

$$
\begin{aligned}
& \mathrm{Fr}=\mathrm{V} \\
& \sqrt{g} \times \mathrm{h} \\
& =\frac{0.3741}{\sqrt{9.8 \times 1}} \\
& =0.143<1 \text { ( aliran sub kritis ) } \\
& =0.33 \times \mathrm{h} \\
& =0.33 \times 1=0.33 \mathrm{~m}=0.3 \mathrm{~m}
\end{aligned}
$$

Untuk hasil perhitungan selengkapnya dapat dilihat pada tabel 4.24 


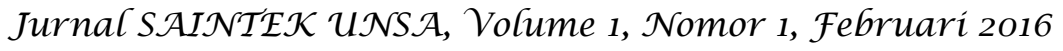

Tabel. 16 Desain saluran drainase Jalan Sultan Kaharuddin KM.02 Kabupaten Sumbawa.

\begin{tabular}{|c|c|c|c|c|c|c|c|c|c|c|c|c|c|c|c|c|}
\hline \multirow{2}{*}{$\mathrm{N}_{0}$} & \multirow{2}{*}{ Lolkasi } & \multirow{2}{*}{ Saluran } & \multirow{2}{*}{$\begin{array}{l}\mathrm{L} \\
\text { (m) }\end{array}$} & \multicolumn{3}{|c|}{ Dimensi } & \multirow{2}{*}{$\mathrm{m}$} & \multirow[t]{2}{*}{ I } & \multirow{2}{*}{ n } & \multirow{2}{*}{$\begin{array}{c}\mathrm{A} \\
\left(\mathrm{m}^{2}\right)\end{array}$} & \multirow{2}{*}{$\begin{array}{c}\text { P } \\
\text { (m) }\end{array}$} & \multirow{2}{*}{$\begin{array}{c}\mathrm{R} \\
(\mathrm{m})\end{array}$} & \multirow{2}{*}{$\begin{array}{c}V \\
(\mathrm{~m} / \mathrm{dt})\end{array}$} & \multirow{2}{*}{$\underset{\left(\mathrm{m}^{3} / \mathrm{dt}\right)}{Q}$} & \multirow{2}{*}{$\mathrm{Fr}$} & \multirow[b]{2}{*}{ (m) } \\
\hline & & & & $\mathrm{b}$ & $\mathrm{B}$ & $\mathrm{h}$ & & & & & & & & & & \\
\hline & \multirow{2}{*}{$\begin{array}{l}\text { J. Sultan } \\
\text { Kaharuddin } \\
\text { KM.02 }\end{array}$} & Kanan & 475 & 0.5 & 1.2 & 1 & 0,333 & 1 & 0.025 & 1.2 & 2.9413 & 0.4080 & 0.3741 & 26.4039 & 0.143 & 0.3 \\
\hline & & $\mathrm{Kin}$ & 475 & 0.5 & 1.2 & 1 & 0,333 & 1 & 0.025 & 1.2 & 2.9413 & 0.4080 & 0.3741 & 26.4039 & 0.143 & 0.3 \\
\hline
\end{tabular}

Sumber : Hasil Analisa

Tabel. 17 Elevasi

\begin{tabular}{|c|c|c|c|c|c|c|}
\hline Lokasi & STA & $\begin{array}{l}\text { Elevasi } \\
(\mathrm{m})\end{array}$ & $\begin{array}{c}\text { Tengah } \\
\text { (m) }\end{array}$ & $\begin{array}{l}\text { Bahu } \\
(\mathrm{m})\end{array}$ & $\begin{array}{c}\text { Kedalaman } \\
\text { Saluran } \\
\text { Eksisting } \\
\text { (m) }\end{array}$ & $\begin{array}{c}\text { Elevasi. } \\
\text { Saluran } \\
\text { Rencana } \\
\text { ( } \mathrm{m} \text { ) }\end{array}$ \\
\hline \multirow{19}{*}{$\begin{array}{l}\text { Ja Sultan } \\
\text { Kaharuddia } \\
\text { KM.02 } \\
\text { Kabupaten } \\
\text { Sumbawa }\end{array}$} & $0+000-0+025$ & 14 & 14 & 13.91 & 12.58 & 12.58 \\
\hline & $0+025-0+050$ & 14 & 14 & 13.91 & 12.58 & 12.83 \\
\hline & $0+050-0+075$ & 14 & 14 & 13.91 & 12.58 & 13.08 \\
\hline & $0+075-0+100$ & 14 & 14 & 13.91 & 12.58 & 13.33 \\
\hline & $0+100-0+125$ & 14 & 14 & 13.91 & 12.58 & 13.58 \\
\hline & $0+125-0+150$ & 14 & 14 & 13.91 & 12.58 & 13.83 \\
\hline & $0+150-0+175$ & 14 & 14 & 13.91 & 12.58 & 14.08 \\
\hline & $0+175-0+200$ & 14 & 14 & 13.91 & 12.58 & 14.33 \\
\hline & $0+200-0+225$ & 15.75 & 15.75 & 15.66 & 14.33 & 14.58 \\
\hline & $0+225-0+250$ & 15.75 & 15.75 & 15.66 & 14.33 & 14.83 \\
\hline & $0+250-0+275$ & 15.75 & 15.75 & 15.66 & 14.33 & 15.08 \\
\hline & $0+275-0+300$ & 15.75 & 15.75 & 15.66 & 14.33 & 15.33 \\
\hline & $0+300-0+325$ & 15.75 & 15.75 & 15.66 & 14.33 & 15.58 \\
\hline & $0+325-0+350$ & 17.5 & 17.5 & 17.41 & 16.08 & 15.83 \\
\hline & $0+350-0+375$ & 17.5 & 17.5 & 17.41 & 16.08 & 16.08 \\
\hline & $0+375-0+400$ & 17.5 & 17.5 & 17.41 & 16.08 & 16.33 \\
\hline & $0+400-0+425$ & 19.25 & 19.25 & 19.16 & 17.83 & 16.58 \\
\hline & $0+425-0+450$ & 21 & 21 & 20.91 & 19.58 & 16.83 \\
\hline & $0+450-0+475$ & 22.75 & 22.75 & 22.66 & 21.33 & 17.08 \\
\hline
\end{tabular}




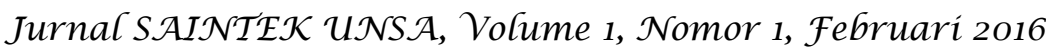

\section{KESIMPULAN}

1. Kapasitas penampungan pada saluran drainase Jalan Sultan Kaharuddin tidak memenuhi untuk menampung debit rencana kala ulang 5 tahun.

2. Model desain dimensi saluran berupa saluran terbuka berpenampang trapesium. Agar mendapatkan desain saluran yang tepat langkah pertama mencoba untuk melakukan normalisasi saluran dibanding kan dengan debit rencana maka dimensi saluran hasil normalisasi masih tidak mampu memenuhi kapasitas debit sesuai dengan rencana kala ulang 5 tahun, maka dari itu perlu dilakukan desain ulang saluran rencana yang tepat agar banjir atau genangan air tidak ada lagi pada ruas jalan Sultan Kaharuddin KM.02 dengan hasil analisa didapatkan dimensi untuk saluran kanan sebesar $B=1.2 \mathrm{~m}, \mathrm{~b}=0.5 \mathrm{~m}, \mathrm{~h}=1 \mathrm{~m}$, dengan debit yang dapat ditampung sebesar $26.4039 \mathrm{~m}^{3} / \mathrm{dt}$, pada saluran kiri $B=1 \mathrm{~m}, \mathrm{~b}=0.5 \mathrm{~m}, \mathrm{~h}$ $=1 \mathrm{~m}$, dengan debit yang dapat ditampung sebesar $26.4039 \mathrm{~m}^{3} / \mathrm{dt}$. Debit hasil rencana ulang dimensi saluran lebih besar dari debit rencana selama 5 tahun yaitu pada saluran kanan $=0.4383 \mathrm{~m}^{3} / \mathrm{dt}$, saluran kiri $=0.4415$ $\mathrm{m}^{3} / \mathrm{dt}$. Sehingga dapat disimpulkan dimensi yang telah direncanakan ulang telah mampu untuk menampung dan mengalirkan debit rencana kala ulang 5 tahun.

\section{SARAN}

1. Diharapkan kepada Pemerintah dan Masyarakat untuk melakukan pemeliharaan rutin drainase agar dapat berfungsi secara efisien sesuai dengan rencana.

2. Kepada pemerintah diharapkan untuk memperhatikan saluran drainase lanjutan atau pembuangan yang terletak pada sebelah kiri samping Gudang (STA 0 + 000), agar kecepatan pengaliran debit air tidak melamban dan menyebabkan genangan pada lokasi tersebut.

3. Daerah kajian merupakan daerah yang dilalui oleh seluruh masyarakat antar Desa, Kecamatan, Kabupaten bahkan Provinsi dari pejalan kaki, kendaraan ringan bahkan kendaraan umum sehingga jika terjadi 


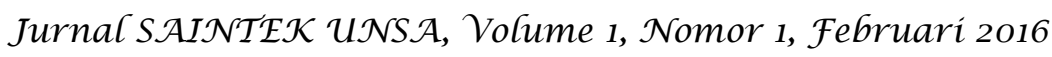

genangan maka banyak masyarakat yang akan mengeluhkan dan terkena dampaknya .

4. Pemerintah perlu membentuk sistem pengawasan drainase kota yang dilakukan oleh petugas khusus.

\section{DAFTAR PUSTAKA}

Anonim. 2014. Data Curah Hujan Dan Hujan Harian. Dinas Pertanian Tanaman Pangan dan Holtikultura Kabupaten Sumabawa

Anonim. 2014. Laporan Kependudukan. Kantor Desa Kerato Kecamatan Unter Iwes

Anonim. 2014. Luas Wilayah atau Peruntukan Lahan. Kantor Desa Kerato Kecamatan Unter Iwes

Anonim. 2015. Peta Topografi. Kantor Badan Perencanaan Daerah Kabupaten Sumbawa

Hasmar, H.A.H. 2012. Drainase Terapan. Ull Press Yogyakarta. Yogyakarta.

Lubis, A.H. dan Terunajaya. 2013. Analisis Intensitas Curah Hujan Maksimum Terhadap Kemampuan Drainase Perkotaan. Universitas Sumatera Utara. Jurnal. Medan.

N.s. 1997. Drainase Perkotaan. Gunadarma, diakses : 6 Juni 2015, http://civilengineering-blog.blogspot.com/2012/03/ebook-drainaseperkotaan.html

Purnama, A, 2015. Konsentrasi Sedimen Suspensi pada Belokan $57^{\circ}$ Saluran Terbuka, Jurnal Unsa Progress. Vol.1, No.3, Oktober, Universitas Samawa, Sumbawa Besar.

Suripin. 2014. Sistem Drainase Perkotaan Yang Berkelanjutan. Yogyakarta : ANDI. Suryaman, H. 2013. Evaluasi Sistem Drainase Kecamatan Pronorogo Kabupaten Pronorogo. Pendidikan Teknik Bangunan Fakultas Teknik. Universitas Negeri Surabaya. Jurnal. Surabaya.

Triatmodjo, B. 2010. HidrologiTerapan. Edisi Kedua. Yogyakarta : Beta Offset.

Yasmin, N.A. 2011. Kajian Sistem Drainase Desa Labuhan Sumbawa Kecamatan Labuhan Badas Kabupaten Sumbawa. Skripsi tidak diterbitkan. Universitas Samawa. Sumbawa Besar. 